\title{
Surgical emergencies, onco-surgeries and colorectal surgeries in COVID-19 pandemic: practical advice based on the global experience and at Dr. D. Y. Patil Medical College, Hospital and Research Centre
}

\author{
Thakut Gowtham, Abhinandan Milind Kadiyal*, Sheetal A. Murchite, Rajendra Madhukar \\ Kulkarni, Vaishali Vinayak Gaikwad
}

\begin{abstract}
Department of Surgery, Dr D Y Patil Medical College and Hospital and Research Center, Kolhapur, Maharashtra, India
\end{abstract}

Received: 26 July 2020

Revised: 08 September 2020

Accepted: 11 September 2020

*Correspondence:

Dr. Abhinandan Milind Kadiyal,

E-mail: drabhinandankop@gmail.com

Copyright: ( $)$ the author(s), publisher and licensee Medip Academy. This is an open-access article distributed under the terms of the Creative Commons Attribution Non-Commercial License, which permits unrestricted non-commercial use, distribution, and reproduction in any medium, provided the original work is properly cited.

\begin{abstract}
The existing coronavirus 2019 (COVID-19) pandemic is challenging healthcare systems at global level. We provide a practical strategy to reform pathways of emergency elective onco-surgery and colorectal surgery in the COVID- 19 pandemic. The novelists, from areas affected by the COVID-19, thought to outline the key-points to be conferred. Responsibilities were allotted, concerning specific characteristics of surgical emergencies, onco-surgery and colorectal surgery during the pandemic, including the administrative management of the catastrophe in India. The endorsements were collected and summarized. During the swift spread of COVID-19, it remains thoughtful to halt non-cancer procedures and prioritize surgical emergencies. Endoscopy, proctological procedures have to be completed selectively. With colorectal emergencies, a conservative approach is recommended. Detailed procedures should be followed when operating on COVID-19 patients, using committed personal protective equipment and adhering to specific rules, containing minimally invasive surgery. These guidelines summarize the strict instruction of entry/ exit into theatres and operating block as well as advice on performing procedures carefully to decrease risk of contracting the virus. It is likely that restructuring of health system is required, at central, state, and district levels. A description of the strategy adopted in Dr. D.Y. Patil Medical College Hospital, Kolhapur is provided. Evidence on the management of patients requiring surgery for surgical emergencies, onco-surgery and colorectal conditions during the COVID-19 pandemic is presently deficient. Healthcare professionals have succeeded with high volumes of surgical patients during the pandemic, could be useful to alleviate some risks and decrease exposure to other patients, public and healthcare staff.
\end{abstract}

Keywords: COVID-19 pandemic, Colorectal surgery, Onco-surgery, Surgical emergency, SARS-CoV2 infection

\section{INTRODUCTION}

Coronavirus pathogens are the great public health threat targeting the respiratory system of humans. The previous outburst of coronaviruses including Severe acute respiratory syndrome (SARS) and the Middle East respiratory syndrome (MERS). ${ }^{1}$ In December 2019, various patients were diagnosed with pneumonia of unknown etiology. However, these patients were linked with seafood and wet animal wholesale market in Wuhan, Hubei Province, China. ${ }^{2,3}$ Further, World health Organization (WHO) on the day February 11, 2020, announced that the disease caused by the novel coronavirus that is COVID-19, which is the acronym of 'coronavirus disease 2019'. ${ }^{4}$ Globally, till 16 May 2020 around 4.7 million people are infected with COVID-19 
with more than 3 lakh deaths. Whereas, in India, the number of infected cases is near to 1 lakh. ${ }^{5}$

The clinical symptoms including cough with or without sputum, sore throat, fever, fatigue, and shortness of the breath are commonly observed in infected subjects. ${ }^{6}$ Literature suggests that nasal cavity and throat are reached with the viral loads and large droplets generated during coughing and sneezing are the common mode of transmission of infection. ${ }^{7,8}$ Moreover, along with oral cavity COVID-19 can be found in the fecal samples of the patient. ${ }^{9-12}$ Therefore, healthcare providers of endoscopy are at higher risk due to endoscopic procedures required short physical distance from patients which may lead to direct contact with patients and aerosol droplets. Guidance on the practice of endoscopy has been posted by the American college of Gastroenterology and the British society of gastroenterology. ${ }^{13,14}$ Despite this Asia has already accumulated substantial experience in combating the COVID-19 outbreak; some regions have shown their ability to prevent outbreaks and maintain a high-quality endoscopy service without subjecting patients and staff to undue health hazards.

The impact of COVID-19 on patients with cancer or with chronic conditions, scheduled for elective non-cancer procedures, and also the healthcare professionals is enormous. ${ }^{15,16}$ Therefore, it is required to reassess the way surgical care is being offered, especially when encountering surgical emergencies, onco and colorectal surgery. The review aimed to provide practical information and instruction for readers to deal with the COVID-19 positive patients from surgeons' perspective with special emphasis on onco-surgery and colorectal diseases. Due to a lack of knowledge regarding COVID19 and its rapid spread, the reader should be aware that some suggestions in this article are the opinions or experiences of experts.

\section{CONSEQUENCES OF COVID-19 ON COLORECTAL CANCER AND INFLAMMATORY BOWEL DISEASE MANAGEMENT}

Globally, COVID-19 infection emphasizing on each feature of various healthcare systems. Whilst higher priority is currently being the treatment of COVID-19 cases. In the case of colorectal surgery, patients diagnosed with cancer and inflammatory bowel disease (IBD) are commonly infected with COVID-19. In Chinese analysis among 1590 COVID-cases, 19 patients had a history of cancer including three cases of colorectal cancer. It has been reported that patients of gastrointestinal cancer are commonly infected by COVID-19 compared to healthy individuals. ${ }^{15}$ According to the Italian National Institute of Health, among the 2003 deaths till 17th March 2020, 72 patients had a history of active cancer. ${ }^{17}$ However, it is so early to consider that cancer patients are at high risk of death from COVID-19, but predominant complications could be expected. This consideration evolves the questions on the patient's management addition to clinical challenges. ${ }^{18}$ In India, the severely affected states such as Maharashtra, Tamil Nadu, Delhi, Gujarat, and other northern states facing the challenge of shortage of medical staff and overwhelming work on the emergency department, intensive care units, and COVID-19 dedicated wards, which required the reallocation of surgeons. Therefore, all elective non-cancer procedures and outpatient clinics are suspended.

In patients who underwent surgery and were due to receive adjuvant treatment, therapy is being postponed on a caseby-case basis when possible. In infected patients, it is reasonable to concede elective medical procedure regardless of whether asymptomatic, because of the assumed danger of worse outcome in case of postoperative complications. ${ }^{19}$ In highly affected areas (Red zone), it is essential to screen the patients in which surgery is mandatory. Patients should encourage extra precautions including using masks and social distancing.

Immunological responses and inflammation are common in IBD patients therefore; immunomodulatory or immunosuppressants are used in the treatment. However, it may increase the risk of infection and susceptibility to COVID-19. Concerning the safety of such patients who are residing in highly affected areas, advanced precautions such as social distancing, regular hand wash, disinfection with hydro alcoholic gel are required during the treatment period. ${ }^{20}$ The impact of the withdrawal of the treatment of IBD flares is more dangerous than COVID-19. According to the international organization for the study of IBD, the patient should have managed with mesalamine and taper steroids. Similarly, no indications to stop biological therapies, facilitating patient's adherence to the enhanced recommendations. ${ }^{20,21}$

SECURE-IBD coronavirus reporting registry has been launched aiming to define the impact of COVID-19 on IBD and to know the effect of factors such as age, comorbidity, and treatment on COVID-19 outcomes. All IBD patients positive to COVID-19 are reported to the registry regardless of severity. So far, seven cases are reported including the hospitalization of one patient without ventilator support.

\section{COVID-19 CONSEQUENCES ON AN ESSENTIAL POINT TO HELP WITH CANCER TRIAGE}

\section{An important consideration for all cancer patients}

The comorbidities and age of the patient are important in evaluating the relative risk and benefit of presenting the patient to coronavirus versus pursuing alternative or nextbest options such as neoadjuvant chemotherapy before the operation.

The availability of resources to the surgeon and hospital at the time of assessment is critical. Since this pandemic is dynamic concerning patient acuity, volume, and hospital resources, the current state and immediate potential future 
state of the hospital system at the time of the proposed operation and anticipated postoperative inpatient recovery needs to be con.

\section{Table 1: COVID-19 phases of hospital or healthcare} system.

\begin{tabular}{|lll|}
\hline Phase & Condition & $\begin{array}{l}\text { Description } \\
\text { No COVID-19 positive } \\
\text { patients, hospital operating as } \\
\text { normal. }\end{array}$ \\
\hline I & Unaffected & $\begin{array}{l}\text { COVID-19 positive patients are } \\
\text { in the hospital, but resources } \\
\text { and Intensive care unit (ICU) } \\
\text { beds/ventilators are not } \\
\text { threatened. }\end{array}$ \\
\hline urgent & & $\begin{array}{l}\text { Many COVID-19 positive } \\
\text { patients are in the hospital, ICU } \\
\text { beds/ventilator availability is } \\
\text { strained, and operative and/or } \\
\text { Personal protective equipment } \\
\text { (PPE) resources are limited. }\end{array}$ \\
& Urgent & $\begin{array}{l}\text { A crisis where most } \\
\text { ICU/ventilator resources are } \\
\text { directed to COVID-19 patients } \\
\text { and operating room and/or PPE } \\
\text { equipment is minimally or } \\
\text { entirely unavailable. }\end{array}$ \\
\hline & Emergent &
\end{tabular}

The urgency of the operation proposed. Hospital systems are embracing that, as resource permits the cancer patients should subject for curative resection due to delayed surgery (>3 months) may lead to an adverse effect on the tumor and oncologic outcome.

Surgical procedures can affect a patient's immune system and the consequences of it may severely affect COVID-19 positive patients. Therefore, depending upon the availability of coronavirus testing, pre-surgery testing is strongly encouraged, which also facilitates the prevention of medical staff.

Open surgery and minimally invasive approaches: In the case of unaffected COVID-19, patient use of laparoscopic or robotic surgery is appropriate. However, in positive patients requiring an urgent operation, the approaches have their considerations. Concerns exist regarding potential viral contamination with pneumoperitoneum during laparoscopic and robotic surgery. Despite the unavailability of evidence, the risk cannot be overlooked and can be avoided by preventive measures as we discussed earlier. In open surgery using electro-surgery or any other approach, the generation of fumes (aerosols) can be considered as a risk of viral spread. In confirmed or suspected patients, the robotic approach involves the potential risk of contamination of equipment with viruses.

The likelihood of the need for ICU: Patients who require more time in hospital or having peri-operative complications are potentially needed ICU or high dependency unit (HDU)/telemetry services that may be also required for COVID patients, should have their operation timed to terminate surge resource constrains and contamination, if possible.

Length of time for recovery: The benefits of minimal invasive surgery with reduced hospital stay and a higher rate of discharge to home, rather than a nursing home, should be considered in planning surgical approaches in COVID negative patients only. ${ }^{22,23}$

Consenting the patient for surgery: Considering the potential risk of surgery during the COVID-19 pandemic, consent should obtain after a clear discussion with the patient and their family about abducting the COVI-19 infection.

\section{COVID-19 CONSEQUENCES ON ENDOSCOPIC PROCEDURES}

The risk of transmission of infection from the asymptomatic patient during endoscopy is high. This may be due to the minimum distance from the patient, aerosol generation, and aspiration of digestive fluids. ${ }^{24}$ Moreover, in the digestive system, the Angiotensin converting enzyme-2 (ACE-2) receptors are commonly present which is a binding site for SARS-CoV-2. In addition, viral RNA has been detected in saliva and stool suggesting that oralfecal contamination as an alternative mode of transmission. ${ }^{25-28}$

COVID-19 positive patients can also develop Gastrointestinal tract (GIT) symptoms evidenced by a previous report of 73 patients admitted for pneumonia. Among these patients, $54.2 \%$ were positive for viral ribonucleic acid (RNA) in stool and $23.3 \%$ were stool positive even virus cleared from respiratory samples. This implies that regardless of the severity of infection virus can remain in stool than any other specimens including nasopharynx and deep throat saliva. ${ }^{28,29}$ However, the knowledge of disease is limited, and various recommendations are based on previous SARS or MERS outbreaks. ${ }^{30}$

After declaration by the government of India national outbreak, recommendations have been released which also supported by the Asian pacific society for digestive endoscopy. Figure 1 shows a potential reaction to the outbreak by a surgery department.

Previous reports recommendation including postponed and rescheduling of endoscopies with outpatient delayed or done by telemedicine or telephone consultation. ${ }^{24,31} \mathrm{We}$ suggest each case should be tracked and assessed in the light of pandemic evolution to decide associated risk for patients with delay. Dedicated team with minimum staff should present at the hospital to respond to urgent or undefeatable procedures. To avoid unnecessary risks and overuse of personal protective equipment, students and trainees should not allow to the department. ${ }^{32}$ Exposure of 
specialist personnel should be avoided to continue service. ${ }^{33}$ In low-resource settings, endoscopy procedure should be used only in life-threatening conditions such as GI bleeding, foreign body removal, food bolus obstruction, and ascending cholangitis. ${ }^{34}$

We recommended a telephonic survey of patients regarding symptoms (fever, cough, and dyspnea) the day before the surgery. Before admission in the department patient should be scanned for fever and should undergo a triage questionnaire to rule out associated risk with the procedure. ${ }^{24,35}$ Repici A et al divided the patients into low risk- no symptoms, no contact with COVID-19, no stay or travel history in COVID-19 area, intermediate-risksymptoms (fever, cough, dyspnea, diarrhea) but no contact COVID-19, or stay in high-risk areas, or no symptoms but exposed to COVID-19 or reside in the risk area, high riskpositive to at least one symptom or contact with COVID19 , residing in the high-risk area from previous 14 days. ${ }^{24}$

Standard precaution measures as per recommendation including the use of mask gloves should be compulsory for patients and health care providers. In the case of low risk and intermediate-risk patients who are scheduled for GI endoscopy, surgical masks, single-use gown, hairnet, and goggles are enough. Whereas in high-risk patients Filtering face pieces (FFP) respirators, such as N95, FFP2/FFP3, double-gloves, water-resistant gown, and goggles must be used. ${ }^{34}$
A COVID route completely separated from the no-COVID route and should be identified. A negative pressure room outside the department would be desirable for the suspected and confirmed COVID-19 patients. Care should be taken during disposing of used equipment such as PPE, scrubs, and shoes used in the endoscopy ward. It is evidenced that contamination virus may occur by staff shoes therefore; disposing of shoes or shoes cover is important. ${ }^{35}$

\section{COVID-19 CONSEQUENCES ON PROCTOLOGY}

During the COVID-19 outbreak, disorders such as proctology, which is a component of colorectal surgery, have been terminated. Except for oncological and urgent cases, all outpatient proctology has been postponed and is due to be rescheduled gradually. However, several proctology disorders including rectovaginal and recto urethral fistulas, precancerous lesions, and anal malignancies may impose a psychological and economic burden on the patient. Being unable to perform diagnostic procedures, ethical concerns are existing due to the associated mortality rate as late or no treatment can cause a high mortality rate than COVID-19.36,37 Moreover, digital rectal examination and anoscopy are important steps of proctology examination, however, the present emergency causes surgeons to use it selectively, due to the risk of contagion intrinsic to such maneuvers.

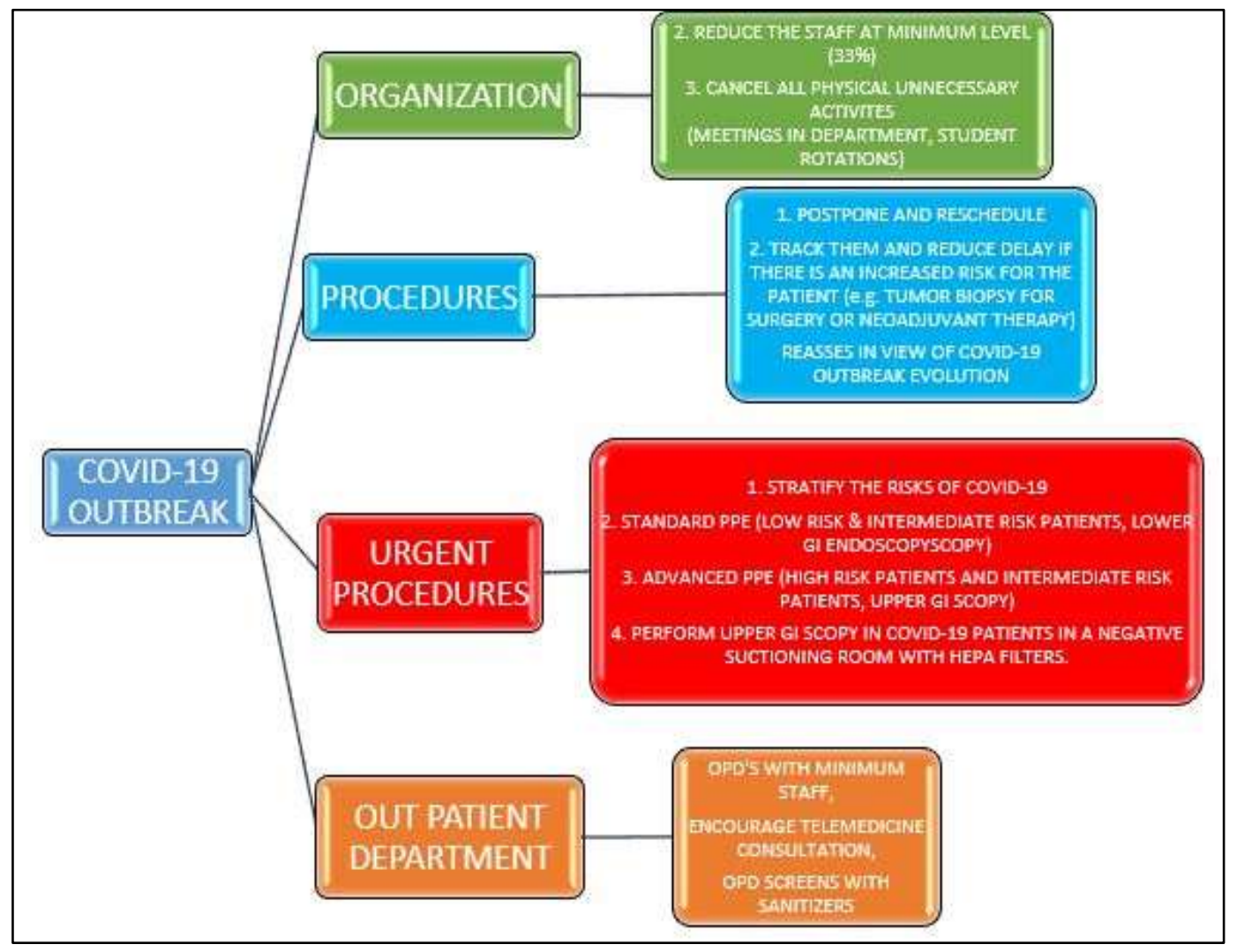

Figure 1: Potential reaction to outbreak by department of general surgery, DYPH, Kolhapur. 
Since elective outpatient consultations are not being done, most of the physicians are leading phone discussion after revising the chart of the patients and those are considered not deferrable are calling to attend the hospital. Similarly, the role of telemedicine is validated in disaster and the same can be included in coloproctology. ${ }^{38-40}$ Incorporation of telemedicine in practice is most likely interesting after the resolution of the pandemic, as it could maintain a strategic distance from physical attendance of the hospital, expect if unavoidable. ${ }^{19}$

Common anorectal emergencies including thrombosed external hemorrhoids, strangulated or bleeding hemorrhoids, anorectal abscesses, anal fissure, and Fournier's gangrene should be timely treated, even if surgery is not always necessary. The attempt should have made to manage the patients susceptible or positive to COVID-19. Conservative measures are possible and effective for thrombosed hemorrhoids. Anorectal septic conditions should be managed using surgical drainage. The incidence of Fournier's gangrene is low but it is associated with a high mortality rate. Therefore, priority should be given to rapid diagnosis and treatment. ${ }^{41}$ On account of proctology strategies during the pandemic, outpatient methods and local anesthesia ought to be supported.

\section{COVID-19 AND EMERGENCY COLORECTAL SURGERY WITH PERIOPERATIVE PRACTICE RECOMMENDATIONS ON HOW TO SAFELY SCRUB AND PROTECTIVE MEASURES/ EQUIPMENT}

Among colorectal emergency surgery, only lifethreatening emergencies such as intestinal perforation, obstruction, and the bleeding should be treated to spare the important resources for the management of the pandemic. Positive COVID-19 patients requiring laparoscopic colorectal surgery should be carefully considered. The potential drawback of the minimally invasive surgery is the aerosolization of the virus, favored by intra-abdominal positive pressure during laparoscopy while in some procedures, long duration of surgery, prolongs anesthesia. Despite this laparoscopy, surgery has an advantage over open surgery (electrocautery) as it reduces the dissemination of aerosol. Precautions must be taken to limit the leakage of gas from the trocars. The use of trocars with the self-sealing Hasson is important to make a small and practicable incision. The trocar trephine must be connected to negative pressure suction with a water seal. Before releasing pneumoperitoneum or making, an extraction incision the insufflator must be turned off and the pneumoperitoneum must be emptied by negative pressure connected to a water seal. The use of laparoscopy should be based on a case-by-case basis, patient, diseaserelated factors, and skills of an expert. In COVID-19 positive emergency cases, we suggest the use of laparoscopy only if appropriate availability of equipment. Pre-operative and intra-operative collaboration with the multidisciplinary and anaesthetic team is vital and or availability of dedicated COVID-19 laparoscopic unit.

Positive patients of upper GI bleeding with Hemodynamic stability should have all conservative management options exhausted first before endoscopy due to the high risk of aerosol-generating procedures. The requirements for such procedures should be risk-assessed and deferred or delayed if possible. Whenever essential then full PPE is required. Non-endoscopic interventions in a stable patient with lower GI bleeding include angiography, with or without angioembolization. Unstable patients or ongoing bleeding patients should be considered for laparotomy; however, outcomes are likely to be poor.

Basic surgical principles should follow in the management of large bowel perforations during the pandemic however, an open approach is recommended. The management algorithm of complicated diverticulitis should also not change by focusing on maximizing conservative options such as antibiotics where possible. ${ }^{42}$ Percutaneous drainage should be risk assessed. Whenever required, definitive surgery and source control should be preferred over laparoscopic lavage. The open abdomen should be avoided, and stage definitive procedure and end stomas should be preferred. Sigmoidectomy should be performed in an emergency as an open procedure and Hartmann preferred over an anastomosis in this particular situation. The use of anastomosis in the emergency setting should be cautious as it is associated with high risk in suspected and positive COVID-19 patients because of the complication rate (anastomotic leaks, intra-abdominal collections) in the procedure is high, and for subsequent consumption of healthcare resources following an anastomotic leak.

\section{Appendicitis management should be tailored to a simple algorithm}

In proven COVID-19 patent who need urgent surgery for perforated appendicitis should be performed by an open approach. However, laparoscopy can be considered if the above-mentioned precautions and devices are available and properly installed in the theatre. Whereas, nonperforated appendicitis should be initially managed with the non-operative approach with antibiotics and ambulatory care where appropriate. Outpatient management of uncomplicated appendicitis with regular telephone follow up is ideal and has already been proven to be safe and effective. ${ }^{43}$ Patients can be re-assessed in telephone clinics at any time during follow up if symptoms are not resolving and readmission considered if deteriorating. All emergency general surgery patients should be tested for COVID-19 immediately. However, emergency surgical management should not be delayed whilst awaiting results with the rationale that all patients during the pandemic should be considered to be COVID19 positive and precautions taken appropriately. 
Table 2. Preventive and protective measures being adopted.

\section{Setting of COVID surgical theatre}

2 teams: 1 inside, 1 outside the theatre.

Team out: Operation theatre (OT) Technician, OT Assistant, cleaning staff.

Team in: OT technician, OT assistant, cleaning staff, anaesthetist, surgical team.

Level 2 Personal PPE in the theatre

Pre-room: Double hair cap, FFP 3 mask, overshoes, neck guard or surgical balaclava, use goggles or a silicone whole face mask / face shield if using eyeglasses, sterile gown and gloves.

\section{Entrance order in theatre}

OT technician, OT assistant, cleaning staff.

Anaesthetist.

Patient (accompanied by the Surgical Ward staff from the area of origin who helps transfer the patient directly to the room on the surgical bed, through dedicated and marked COVID path) entrance in the Theatres Block from the emergency door adjacent to the operating theatre.

Surgical team

Once inside the theatre:

Second sterile gown, second pair of gloves.

\section{Exit from surgical theatre}

The department (ward or ICU of destination is alerted via Phone and prepares the bed; outside staff physically goes to take the bed in the ward and brings it to the Operating Block.

Inside staff take the bed inside the operating room and transfer the patient from the table to the bed.

Procedure to leave the theatre

When leaving the theatre, the staff undresses in the filter area, then following a dedicated path. It is important to take off the theatre gown with great care so as not to spread the virus and to remove the facemask as the last procedure and immediately put on a clean one. The team goes to the changing room (the one closest to the operating room), there takes a whole-body shower and then changes uniform before exiting.

\section{Exit order}

Surgical team.

OT assistant.

Anaesthetist without changing wear, they take the patient to the ward of destination (or ICU) following the COVID dedicated path (which is then fully sanitized after operations are completed) together with the outside cleaning staff and Nurse who precede them and act as "forerunners" opening the doors, pushing for the lift and making sure that the path is isolated. Inside cleaning staff sanitizes the operating room, then exit and change their scrubs following the same rules as above

PPE: Personal protective equipment
The staff involved in surgery, operation theatre must be well trained to use personal protection equipment (PPE), and all the procedures must be clearly defined and standardized. The pandemic does not eliminate the need to adhere to the perioperative surgical checklist and should be prioritized to improve communication in a high-stress environment. Patients should be reviewed, intubated, and recovered within the theatre to restrict contamination to just one room; the pathway to the theatres must be the shortest possible on a previously defined route, involving minimal contact with others. The number of staff involved in the surgery should be limited and the traffic in theatres should be restricted. ${ }^{44}$

The preventing and protective measures adopted in the department of General Surgery, Dr. D. Y. Patil Medical College, Hospital and Research Centre, Kolhapur are summarized in Table 2.

\section{Healthcare policy and Government of India Perspective}

In emergencies, it is required to reframe and reset the priority and "yardsticks" that one would use everyday practice. During the COVID-19 outbreak, before the declaration of a pandemic, the Government of India was promptly reacted with a timely planning strategy to face the situation. At the time of developing guidance suitable during the COVID-19 crisis, the priority of the Government was to protect the citizens, healthcare providers, patients with COVID-19, and not patients with other treatable conditions and those requiring emergency treatment for acute diseases and trauma. ${ }^{15,17}$

Indian Government chose to establish hospitals dedicated to COVID-19 patients and other suitable hospitals as referral centres to deal with surgical emergencies and elective surgical procedures. These centres were identified at a local level and established after meetings of the Regional Collectors of each Region. The directives of the Central Government required the local institution to identify several hospitals per each region that would have been used for the treatment of COVID-19 only, thereby better distributing the amount of work between centres, and allowing a better allocation of resources. The reduced availability of instrumentation and the demand for intensive care beds further highlights the importance of adequately distributing tasks/ resources between dedicated COVID-19 and strict non COVID-19 hospitals.

Specific pathways of referrals were agreed such as patients requiring cancer surgery were regarded as a high priority. However, further sub-classification of priority was required to identify those needing expedited surgical treatment, and those in whom a watchful waiting approach might be acceptable. During the early epidemics, a document by a panel of oncologists was circulated in all hospitals, the draft contains a classification of priority suitable for patients with colorectal cancer during the COVID-19 outbreak. Cancer patients were prioritized based on tumour features and patient-associated factors 
(age and comorbidities, graded using the American Society of Anesthesiologists' (ASA) score). Three different categories of priorities were hence established, each identified with a color:

High priority (Red), including cancer-associated emergencies, not amenable to endoscopic or non- surgical treatment, with any ASA score if the patient is <80-yearof-age, or in ASA 1-2 in case of older patients (patients $>80$ years-of-age with ASA 3-4 graded as "intermediate priority"); surgery should be performed within 2 weeks.

Intermediate priority (yellow): Cancers that are potentially curable with surgery, without any pharmacological, endoscopic, radiotherapy alternatives, in patients of any age, with ASA 1 or 2 (patients above 80 years-of-age with ASA 3-4 assigned to "low priority"); surgery should be performed within 2 months.

Low priority (green): Cancers amenable to pharmacological, endoscopic, radiotherapy, and early cancers (i.e. T1N0) or with low aggressiveness; surgery can be deferred over 2 months.

Specific tumour features associated with prognosis were provided for each category, to aid the decision-making.

Presently, it is impossible to conclude the performance of such measures due to the decision of which specific elective procedures and the number of procedures to be performed were not strictly regulated. Speculating on data about the procedures performed in each hospital or each region is of limited value at this stage and could be misleading because most documents of discharge and clinical charts might not be available.

Lastly, dedicated monitoring measures were put in place, to detect any shortages in instrumentations or deficiencies which might jeopardize the adequate provision of care or expose the healthcare professionals to unacceptable working conditions, and to identify the critical areas needing immediate action.

Discussions are going on for the post-pandemic strategies, which would need a careful reassessment of the situation and might need the development of a dedicated plan, which could probably require international aids and collaboration.

\section{CONCLUSION}

COVID-19 pandemic is seriously threatening the structure of healthcare systems globally, and many interventions are required to deal with the new scenario after the crisis has been controlled. The present manuscript was designed to provide an overview of how some areas of onco-surgery, colorectal surgery can be reorganized during the emergency. Far for being a definitive and authoritative guideline, the contents of this document are to be regarded as advice and guidance during a time of unprecedented demand on global healthcare systems.

For those facing the crisis, it would be helpful to consider an in-depth reorganization of surgical emergencies, oncosurgeries, and colorectal service at a central and local level. The limited availability of surgical theatres, the reduced number of staff members, the limited hospital beds and resources, make it necessary to perform only prioritized elective onco-surgeries and colorectal procedures. The conservative management of COVID-19 positive patients with diseases of surgical interest should be as conservative as possible, without exposing the patients and health care providers to unnecessary risks.

The surgical staff must adhere to strict perioperative pathways and must receive adequate training and instructions. Adherence to rules should be accompanied by common sense and decisions should be taken swiftly but based on efficient team-working and cross-specialty collaboration.

\section{Funding: No funding sources Conflict of interest: None declared \\ Ethical approval: Not required}

\section{REFERENCES}

1. Rothan HA, Byrareddy SN. The epidemiology and pathogenesis of coronavirus disease (COVID-19) outbreak. Journal of autoimmunity. 2020;26:102433.

2. Bogoch II., Watts A, Thomas-Bachli A, Huber C, Kraemer MU et al. Pneumonia of Unknown Etiology in Wuhan, China: Potential for International Spread Via Commercial Air Travel. Journal of Travel Medicine. 2020;27(2):taaa008.

3. Lu H, Stratton CW, Tang YW. Outbreak of Pneumonia of Unknown Etiology in Wuhan China: the Mystery and the Miracle. J Med Virol. 2020;92:401-2.

4. Cascella M, Rajnik M, Cuomo A, Dulebohn SC, Di Napoli R. Features, evaluation and treatment coronavirus (COVID-19). StatPearls Publishing. 2020. Available at: https://www.ncbi.nlm.nih .gov/books/NBK554776/ Accessed on 16 May 2020.

5. Worldometer. $2020 . \quad$ Available at: https://www.worldometers.info/coronavirus/. Accessed on 16 May 2020.

6. Guan WJ, Ni ZY, Hu Y, Liang WH, Ou CQ, He JX et al. Clinical characteristics of coronavirus disease 2019 in China. N Engl J Med. 2020;382(18):170820.

7. Rothe C, Schunk M, Sothmann P, Bretzel G, Froeschl G, Wallrauch C et al. Transmission of 2019-nCoV infection from an asymptomatic contact in Germany. N Engl J Med. 2020;382(10):970-71.

8. Zou L, Ruan F, Huang M, Liang L, Huang H, Hong $\mathrm{Z}$ et al. SARS-CoV-2 viral load in upper respiratory specimens of infected patients. New N Engl J Med. 2020;382(12):1177-79. 
9. Gu J, Han B, Wang J. COVID-19: gastrointestinal manifestations and potential fecal-oral transmission. Gastroenterology. 2020;158(6):1518-19.

10. Song Y, Liu P, Shi XL, Chu YL, Zhang J, Xia J et al. SARS-CoV-2 induced diarrhoea as onset symptom in patient with COVID-19. Gut. 2020;69(6):1143-44.

11. Zhang J, Wang S, Xue, Y. Fecal specimen diagnosis 2019 novel coronavirus-infected pneumonia. J Med Virol. 2020;92(6):680-82.

12. Xiao F, Tang M, Zheng X, Liu Y, Li X, Shan H. et al. Evidence for gastrointestinal infection of SARSCoV-2. Gastroenterology. 2020;158(6):1831-33.

13. American College of Gastroenterology Joint GI Society Message on COVID 19. 2020. Available at: https://gi.org/2020/03/15/joint-gi-society-messageon-covid-19/. Accessed on 16 May 2020.

14. British Society of Gastroenterology. Endoscopy activity and COVID-19: BSG and JAG guidance. 2020. Available at: https://www.bsg.org.uk/covid19-advice/endoscopy-activity-and-covid-19-bsgand-jag-guidance/ Google Scholar. Accessed on 16 May 2020.

15. Mao R, Liang J, Shen J, Ghosh S, Zhu LR, Yang H, et al. Chinese Society of IBD, Chinese Elite IBD Union; Chinese IBD Quality Care Evaluation Center Committee. Implications of COVID-19 for patients with pre-existing digestive diseases. Lancet Gastroenterol Hepatol. 2020;30076-5.

16. Liang W, Guan W, Chen R, Wang W, Li J, Xu K, et al. Cancer patients in SARS-CoV-2 infection: a nationwide analysis in China. Lancet Oncol. 2020;21(3):335-37.

17. Istituto Superiore di Sanità. Report sulle caratteristiche dei pazienti deceduti positivi a COVID- 2019 in Italia. 2020. Dati al 17 marzo 2020 Available at: https://www.epicentro.iss.it/coronavirus/sars-cov-2-decessi- italia. Accessed on 16 May 2020.

18. Pellino G, Spinelli A. How COVID-19 Outbreak Is Impacting Colorectal Cancer Patients in Italy: A Long Shadow Beyond Infection. Dis Colon Rectum. 2020. Accessed on 16 May 2020.

19. Spinelli A, Pellino G. COVID-19 pandemic: perspectives on an unfolding crisis. Br J Surg. 2020.

20. Crohn's \& Colitis foundation UK, Cronavirus (COVID-19): Advice for people with Crohn's and Colitis. 2020. Available at: https://www.crohn sandcolitis.org.uk/news/coronavirus-covid-19advice. Accessed on 16 May 2020.

21. IOIBD Update on COVID19 for Patients with Crohn's Disease and Ulcerative Colitis. 2020. https://www.ioibd.org/ioibd-update-on-covid19-forpatients-with-crohns-disease-and-ulcerative- colitis/. Accessed on 16 May 2020.

22. Delaney CP, Chang E, Senagore AJ. Clinical Outcomes and Resource Utilization Associated with Laparoscopic and Open Colectomy Using a Large National Database. Ann Surg. 2008;247:819-24.

23. Gerber MH, Delitto D, Crippen CJ. Analysis of the Cost Effectiveness of Laparoscopic
Pancreatoduodenectomy. J Gastrointest Surg. 2017;21:1404 -10.

24. Repici A, Maselli R, Colombo M. Coronavirus (COVID-19) outbreak: what the department of endoscopy should know. Gastrointest Endosc. 2020;S0016-5107(20)30245-5.

25. Wan Y, Shang J, Graham R, Baric RS, Li F. Receptor recognition by novel coronavirus from Wuhan: An analysis based on decade-long structural studies of SARS. J Virol. 2020;JVI.00127-20.

26. To KK, Tsang OT, Chik-Yan Yip C. Consistent detection of 2019 novel coronavirus in saliva. Clin Infect Dis. 2020; ciaa149.

27. Young BE, Ong SWX, Kalimuddin S. Epidemiologic Features and Clinical Course of Patients Infected With SARS-CoV-2 in Singapore. JAMA. 2020;e203204.

28. Zhang J, Wang S, Xue Y. Fecal specimen diagnosis 2019 novel coronavirus-infected pneumonia. J Med Virol. 2020;10.1002/jmv.25742.

29. Gu J, Han B, Wang J. COVID-19: Gastrointestinal manifestations and potential fecal-oral transmission. Gastroenterology. 2020;S0016-5085(20)30281-X.

30. Peeri NC, Shrestha N, Rahman MS. The SARS, MERS and novel coronavirus (COVID-19) epidemics, the newest and biggest global health threats: what lessons have we learned? Int J Epidemiol. 2020; dyaa033.

31. Adams JG, Walls RM. Supporting the Health Care Workforce During the COVID-19 Global Epidemic. JAMA. 2020.

32. Wong TW, Lee CK, Tam W. Cluster of SARS among medical students exposed to single patient, Hong Kong. Emerg Infect Dis. 2004;10(2):269-76.

33. Joint GI Society Message on COVID-19. 2020. https://gi.org/2020/03/15/joint-gi-society-messageon- covid-19/. Accessed on 16 May 2020.

34. Tse F, Borgaonkar M, Leontiadis GI. COVID-19: Advice from the Canadian Association of Gastroenterology for Endoscopy Facilities. 2020. https://www.cag- acg.org/images/publications/CAGStatement-COVID-\&-Endoscopy.pdf. Accessed on 16 May 2020.

35. Razai MS, Doerholt K, Ladhani S, Oakeshott P. Coronavirus disease 2019 (covid-19): a guide for UK GPs. BMJ. 2020;368:m800.

36. Zhou F, Yu T, Du R. Clinical course and risk factors for mortality of adult inpatients with COVID-19 in Wuhan, China: a retrospective cohort. Lancet. 2020;S0140-6736(20)30566-3.

37. Weiss P, Murdoch DR. Clinical course and mortality risk of severe COVID-19. Lancet 2020 10.1016/S0140-6736(20)30633-4.

38. Lurie N, Carr BG. The role of telehealth in the medical response to disasters. JAMA Intern Med. 2018;178:745-6

39. Augestad KM, Sneve AM, Lindsetmo RO. Telemedicine in postoperative follow-up of STOMa PAtients: a randomized clinical trial (the STOMPA trial). Br J Surg. 2020;107(5):509-18. 
40. Kontovounisios C, Smith J, Dawson P, Warren O, Mills S, Von Roon A et al. The Ostom-i ${ }^{\text {TM }}$ Alert Sensor: a new device to measure stoma output. Tech Coloproctol. 2018;22(9):697-701.

41. Gallo G, Martellucci J, Sturiale A. Consensus statement of the Italian society of colorectal surgery (SICCR): management and treatment of hemorrhoidal disease. Tech Coloproctol. 2020;24(2):145-164.

42. Lambrichts DPV, Birindelli A, Tonini V, Cirocchi R, Cervellera M, Lange JF et al. The Multidisciplinary Management of Acute Complicated Diverticulitis. Inflamm Intest Dis. 2018;3(2):80-90.

43. Di Saverio S, Sibilio A, Giorgini E, Biscardi A, Villani S, Coccolini F, et al. The NOTA Study (Non Operative Treatment for Acute Appendicitis): prospective study on the efficacy and safety of antibiotics (amoxicillin and clavulanic acid) for treating patients with right lower quadrant abdominal pain and long-term follow-up of conservatively treated suspected appendicitis. Ann Surg. 2014;260(1):109-17.

44. Wong J, Goh QY, Tan Z, Lie SA, Tay YC, Ng SY et al. Preparing for a COVID-19 pandemic: a review of operating room outbreak response measures in a large tertiary hospital in Singapore. Can J Anaesth. 2020.

Cite this article as: Gowtham T, Kadiyal AM, Murchite SA, Kulkarni RM, Gaikwad VV. Surgical emergencies, onco-surgeries and colorectal surgeries in COVID-19 pandemic: practical advice based on the global experience and at Dr. D. Y. Patil Medical College, Hospital and Research Centre. Int Surg J 2020:7:3531-9. 